\title{
Bilateral Encephaloclastic Lesions In A 26 Week Gestation Fetus: Effect On Neuroblast Migration
}

\author{
MARGARET G. NORMAN
}

SUMMARY: A 26 week gestation fetus with bilaterally symmetrical encephalo. clastic lesions in the cerebral hemispheres is described. Information about gestation allows dating of the cerebral insult to the 34 th fetal month. The history and morphology in this case suggest that insults occurring at or before the 3-4th fetal month interfere with normal neuroblast migration. producing a cerebral scar containing a band of neuroblasts arranged without order or lamination.

RESUMÉ: Nous décrivons des lésions encéphaloclastes bilatérales et symmétriques aux hémisphères cérébraux chez un foetus à 26 semaines de gestation. Telle information nous permet de situer l'insulte cérébrale au 3-4ème mois foetaux. L'Histoire et la morphologie de ce cas suggèrent que si les insultes se produisent avant ou au moment des 3-4ème mois foetaux, il y a interférence avec la migration normale des neuroblastes, produisant ainsi une cicatrice cérébrale avec une bande de neuroblastes désordonnés et non laminés.

From the Division of Pathology, Eleanor $\mathbf{M}$ Paterson, Department of Laboratory Medicine, Children's Hospital of Eastern Ontario and Department of Pathology, University of Ottawa, Ottawa, Ontario.

Presented in part as Case 3. Diagnostic Slide Session, Canadian Association of Neuropathologists, Eighteenth Annual Meeting. Toronto, September 22, 1978.

Reprint requests to Dr. M.G. Norman, Children's Hospital, 250 West 59 th Avenue, Vancouver, B.C., VSX $1 \times 2$.

\section{INTRODUCTION}

Lesions seen early in their evolution inform us more about pathological processes than do old, burnt-out scars. Infants' brains may contain old, scarred lesions. The cause and evolution of these is speculative because data about antenatal life are often fragmentary or absent. This case is being reported because historical data allow us to date with more than usual certainty the time in fetal life at which the insult probably occurred. The resulting morphology tells us what effect the timing of the lesion has on migration of neuroblasts to the cerebral cortex, and the young age at which the resulting lesion was observed is infrequently seen.

\section{CASE REPORT}

Labor began spontaneously at 26 weeks' pregnancy in a Gravida ii, Para i 27 year old woman. Her pregnancy had been complicated by a single episode of vaginal bleeding at three months. A macerated fetus with crown-rump length of $13 \mathrm{cms}$. and weighing 74 grams, was delivered first, then the infant described in this report was delivered as a precipitate vertex. The Apgar score was 5 at 1 minute, and 10 at 5 minutes. The birth weight was 800 grams. Over the next 5-6 hours the infant became increasingly cyanosed and distressed and he was transferred to the Children's Hospital of Eastern Ontario. He was dusky when not receiving oxygen. Peripheral pulses were poor. Arterial gases on intermittent positive pressure ventilation $\mathrm{Fi} \mathrm{O}_{2}$ of $60 \%$ were: $\mathrm{pH} 7.26, \mathrm{pCO}_{2} 40 \mathrm{~mm} \mathrm{Hg}$, $\mathrm{pO}_{2} 94 \mathrm{~mm} \mathrm{Hg}$, base excess $-10, \mathrm{HCO}_{3}$ $17 \mathrm{mEq} / 1, \mathrm{CO}_{2} 18 \mathrm{mEq} / \mathrm{l}$. Over the next few hours the $\mathrm{Fi} \mathrm{O}_{2}$ was increased to $80 \%$, then to $90 \%$. The infant became increasingly hypoxic and acidotic. At 17 hours of age a left pneumothorax was drained. Surgical emphysema developed in the neck. The infant's condition was considered hopeless, ventilation was stopped and he died at $18-1 / 2$ hours of age.

The placenta was diamniotic, monochorionic, and weighed 250 gram. The umbilical cord of the stillborn twin was inserted velamentously into the membranes between the two sacs $1.5 \mathrm{cms}$. from the insertion of the cord of the living twin.

Necropsy of the liveborn twin showed the brain weighed 62.5 grams (normal 107-111 grams). The calvarium was the same size as the brain. Fissures extended on the lateral surface of the brain from the insula almost to the occipital pole (Fig. 1). The leptomeninges were bound down in the fissures. The fissures were the bases of ill-defined triangular chalky yellow areas extending from the pial surface into the cerebral mantle. The microscopic appearance of both lesions was similar. At the periphery of the lesion cortex was normal (Fig. 2). At the edge of the lesion, the cortical ribbon narrowed and became looped (Fig. 3). The looped cortex was not divided into laminae. In the centre of the lesion no normal cortex was present, and a band of primitive cells extended unevely from the ventricle to the pial surface. At the deep edges of the lesion, there was discrete round clusters of primitive cells. In other places bands of cells created an effect like ripples. Most of the nuclei were small and dark and looked like neuroblasts, while a few other scattered nuclei were slightly larger, more vesicular and might have been astrocytes. A few foamy macrophages were scattered through the lesion. The cells were less dense than in normal cortex. There was a coarse, irregular fibrillary background. Holzer stain for glial 


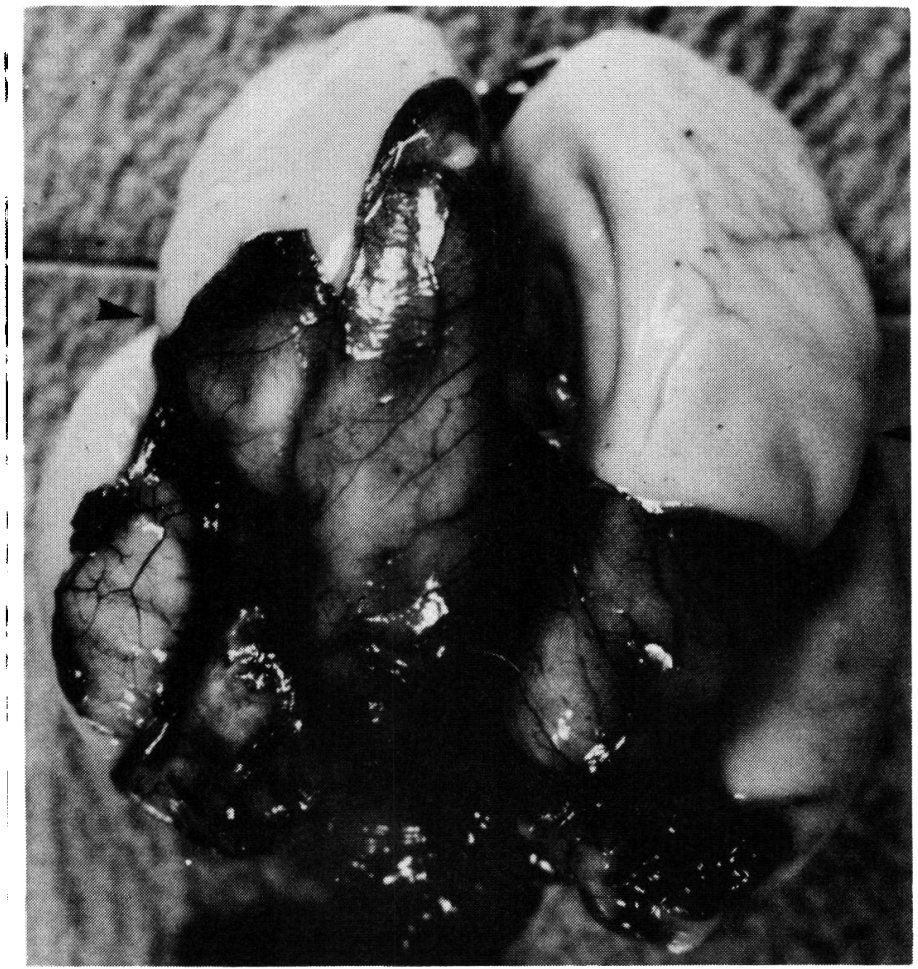

Figure 1 - Note smooth surface, normal at 26 weeks' gestation, of the brain which has been partially stripped of leptomeninges. Clefts are marked with arrows.

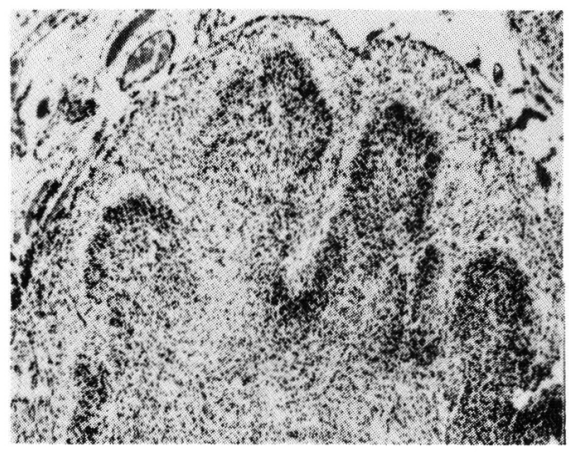

Figure 3- Edge of cleft on other side. Note presence of external granular layer and looping of damaged cortex. Haematoxylin and Eosin X 44 .

fibrils was negative. There was a single focus of calicification in this band of cells. Capillaries were increased in the lesion, and at the pial surface were more numerous, and larger than normal. In the leptomeninges there were a few round glial masses separate from underlying brain. A similar separate wedge-shaped scar lay next to the left thalamus based on ependyma and it contained clusters of irregularly distributed neuroblasts, and a few irregular linear deposits of calcium.

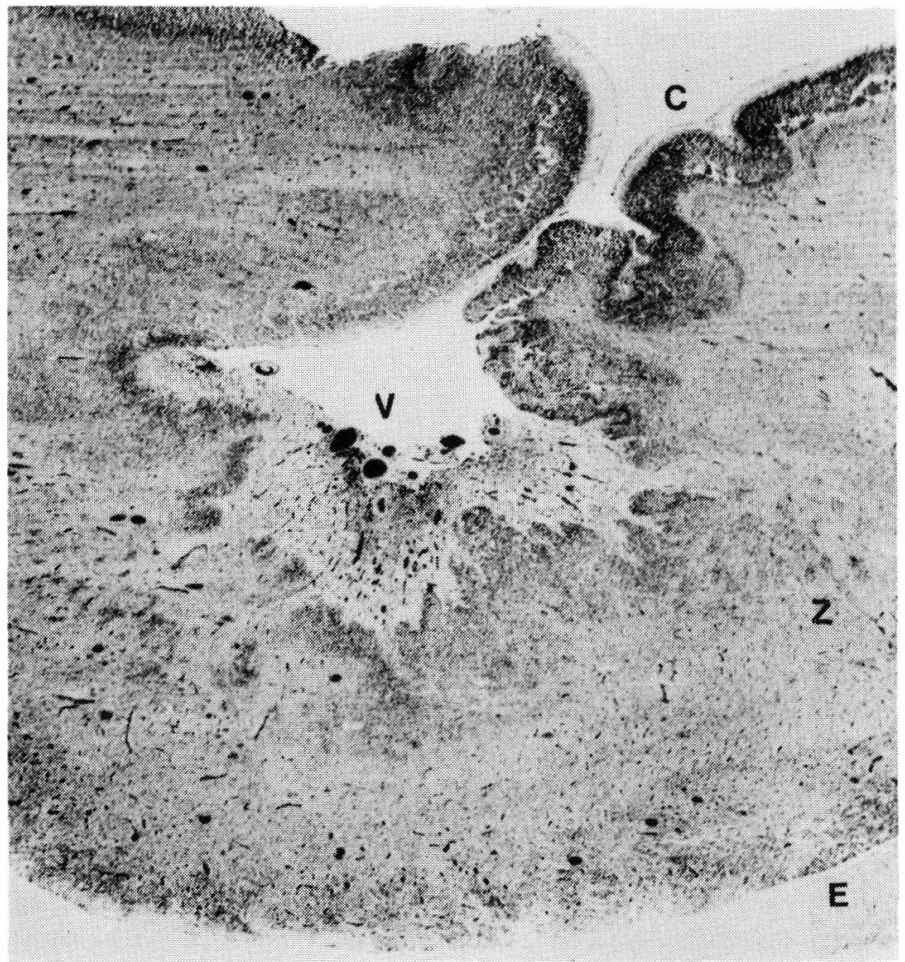

Figure 2 - Low power microphotography of clefts. C: Normal cortex. V: Abnormal vessels at pial surface in depths of clefts. E: Ependyma. Z: Clusters of cells. Haematoxylin and Eosin X 14.5
Other autopsy findings were hyaline membrane disease, focal pulmonary hemorrhage, interstitial emphysema of the mediastinum, focal ulceration of the esophagus and a small fibrotic hemosiderin-containing scar in the spleen.

\section{DISCUSSION}

This infant was microcephalic at 26 weeks' gestation. Growth charts indicate that the brain was preferentially affected (Fig. 4). Since the brain and calvarium were the same size, the insult must have occurred well before birth, with growth of the damaged brain up to the size of the calvarium and subsequent congruent growth of brain and calvarium. The vessels on the pial surface were abnormal, suggesting damage to the developing vessels. Flow in these damaged, abnormal vessels might have been slower than normal, with perhaps a "steal" phenomenon through them, which would further damage the underlying cortex.

In the cortical lesion a disordered mass of cells without lamination extended from ventricle to pial surface with discrete clusters of primitive cells near the ventricles. The lesion was clearly destructive, with foamy macrophages and calcifications. No astrocytic fibrils could be stained by conventional stains. Although glial fibrillary acidic protein is demonstrable at 10 weeks' gestational age (Choi and Lapham, 1978), only the astrocyte processes are present in the cortex, all the cell bodies in the cortex are neuroblasts (Ikuta, et al, 1979) which may explain the lack of glial scarring at this gestational age.

The case most comparable in age to this is the 27 week fetus described by Richman et al (1974). Their case had a polymicrogyric cortex with four laminae without the total disarray seen in this case. They suggested damage occurred after migration was complete at 16 - 18 weeks but before delivery at 27 weeks' gestation resulting in the four-layered microgyric cortex. "Microgyria" or polymicrogyria describes a group of heterogeneous malformations of the brain in which there is an 


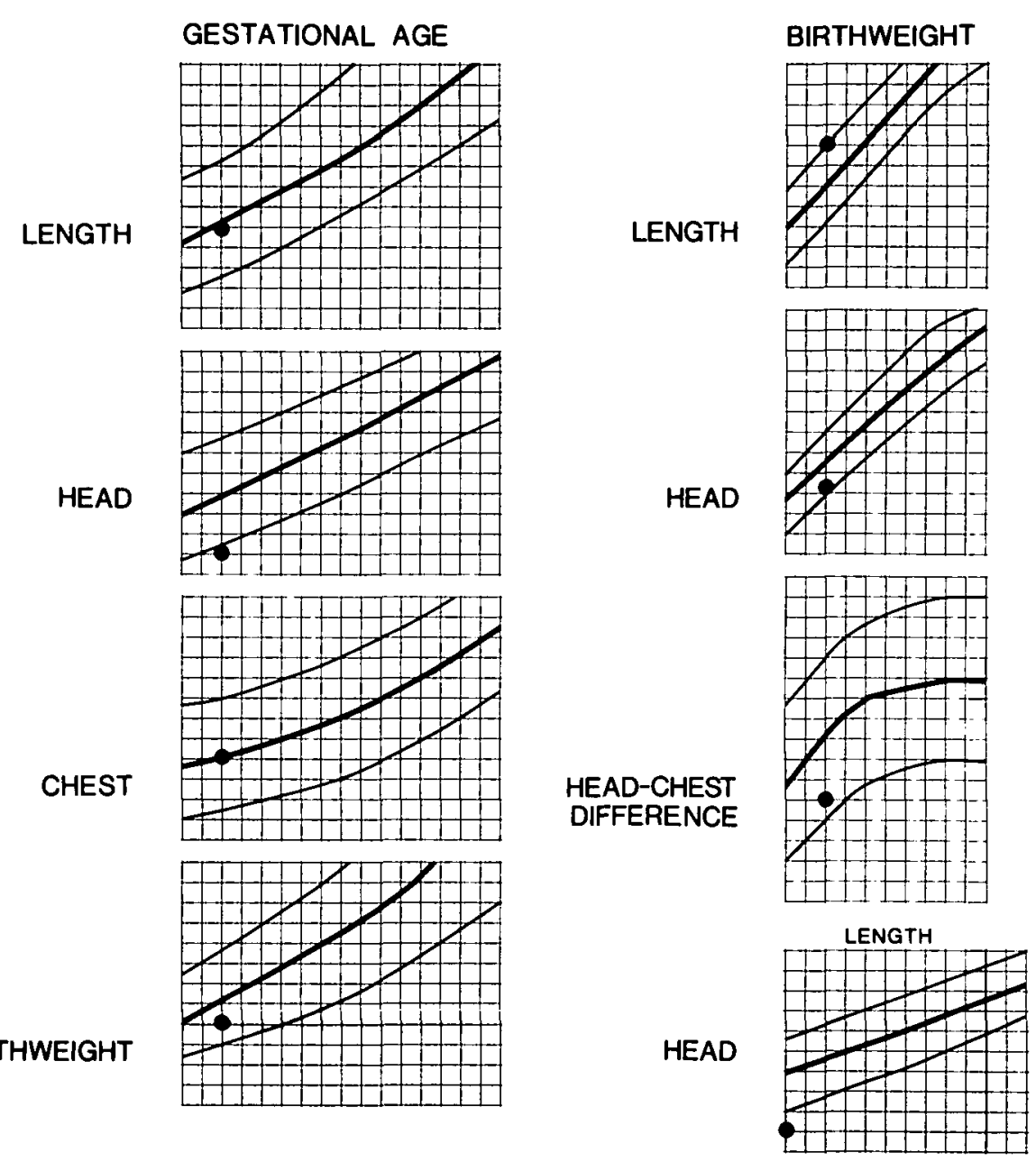

Figure 4-Growth charts (Usher and McLean, 1969). Note head is much more da maged than rest of body.

excessive number of small, abnormal convolutions of the cerebral cortex. Classic microgyria is characterized by a four-layered cortex which may occur alone or in association with other cerebral malformations. Levine et al (1974), Richman et al (1974), and Williams et al (1976) reviewed the early literature in detail and described their own cases which led them to conclude that the four-layered cortex seen in classical microgyria was the result, not of abnormal migration as suggested by Bielschowsky, but of a destructive process. They suggested microgyria was due to laminar cortical necrosis affecting layers III-V, the necrosis being caused by ischemia occurring between the fifth and seventh fetal months after neuroblast migration was complete. Certainly it is interesting to compare the morphology of this case to that described by Richman et al (1974). If we are correct in our inferences about when the damage occurred, it gives us some idea of how differing times of insult affect the final morphology.

Dvorvak et al (1978) produced necrosis of the cortex of newborn rats by freezing the brain. In the process of healing a four-layered cortex appeared, and they interpreted their results as indicating that the four-layered cortex could be produced by an insult occurring during neuroblast migration. As they pointed out, the four-layered cortex could be produced either during neuroblasts migration or by loss of neurones after migration was complete as suggested by Williams et al (1976). Data are as yet insufficient to choose between these alternatives; indeed, both may occur.

If this infant had survived, the deep clusters of cells would probably have developed into deep heterotopias of mature neurons. The scarred area would have grown slightly or not at all, leaving a band of aberrant cells extending from ventricle to pia, while the surrounding brain continued to grow. The result would probably have been a "schizencephaly" of the type that Yakovlev and Wadsworth (1946) regarded as the "failure of growth and differentiation of the circumscribed areas of the cerebral wall during the first two months of fetal life", although they also ascribed some cases of schizencephaly to encephaloclastic processes. This case supports the idea that a destructive insult occurring sometime before migration is complete could result in the appearance of "schizencephaly", probably all cases of which should be regarded as acquired destructive lesions, rather than failures of formation.

To explain the appearance in this case, normal neuronal migration will be considered briefly. Radial glial processes, present at 7 weeks gestational age (Choi and Lapham, 1978), extend from ependyma to pia and serve as guides along which neuroblasts migrate outward. In the cortex the earliest migrating neuroblasts assume that the deepest position, while subsequent migrations occur through this deep layer, with the last migrating neuroblasts taking the most superficial position in the cortex - the so-called "inside-out" migration (Sidman and Rakic, 1973).

It is possible to speculate about differnt mechanisms which might interfere with normal migration of neuroblasts to the cortex. If the radial glia which act as guides are abnormally positioned, then presumably migration will be abnormal. An insult destroying the radial astrocytic processes could result in abnormalities of migration, probably resulting in persistence of deep heterotopias of neurons. An insult not severe enough to destroy the glia might still delay neuronal migration along the processes, either with neurones not arriving at the cortex at all and persisting as deep heterotopias, or failing to complete migration through the already normally positioned earlymigrating neuroblasts. The latestacting mechanism would be loss of neurones from cortex at some time 
after migration has been completed. No direct evidence exists to prove whether some, all or none of these mechanisms operate to produce abnormal migration in the human. Authors have made inferences from their observations on human brains examined weeks or years after the original insult occurred. The inferences have often been made without certain knowledge of the nature, severity or timing of the insult.

In this case, historical data indicated two times when damage might have occurred. One is at 12 weeks when the mother bled vaginally, which might have produced fetal hypotension resulting in ischemia. The second time is at 17 weeks, for the crownrump length of the dead twin suggested it lived till 17 weeks. A circulatory problem occurring in the monochorionic placenta might have occurred at about 17 weeks, or even subacutely over a period of time prior to 17 weeks resulting in death of one twin and hypotension with survival with cerebral damage in the other. Damage could have occurred at both 12 and 17 weeks as well. These historical data date the occurrence of the insult to the 3 - 4th month, before migration of neurons to the cortex was complete, a conclusion supported by the morphological observations, which showed a profound disturbance of neuroblast migration. The historical data lead me to infer that some type of circulatory problem was the cause of the lesion, but it is not possible to say how severe the insult was, whether there was more than one insult, or why the damage was located as it was.

\section{REFERENCES}

CHOI, B.E., LAPHAM, L.W. (1978). Radial glia in human fetal cerebrum: A combined Golgi, immunofluorescent and electron microscopic study. Brain Research 148: 295311.

DVORÁK, I., FEIT, J., JURÁNKOVÁ, Z. (1978). Experimentally induced focal microgyria and status verrucosus deformis in rats - pathogenesis and interrelation. Histological and autoradiographical study. Acta Neuropathol. (Berl), 44: 121-129.
IKUTA, F., OHAMO, E., YAMAZAKI, K., TAKEDA, S., EGAWA, S., ICHIKAWA, T. (1979). Morphology of migrating glial cells in normal development, neoplasia and other disorders. Progress in Neuropatho$\operatorname{logy} 4,377-404$.

LEVINE, D. N., FISHER, M.A., CAVINESS, V.S. JR. (1974). Porencephaly with microgyria: a pathologic study. Acta Neuropathol. (Berl), 29:99-113.

RICHMAN, D.P., STEWART, R.M., CAVINESS, V.S. JR. (1974). Cerebral microgyria in a 27 week fetus: an architectonic and topographic analysis. J. Neuropath. and Exp. Neurol. 33: 374-384.

SIDMAN, R. L., RAKIC, P. (1973). Neuronal migration, with special reference to the developing human brain: a review. Brain research 62: 1-35.

USHER, R. and McLEAN, F. (1969). Intrauterine growth of live-born Caucasian infants at sea-level: Standards obtained from measurements in 7 dimensions. J. Pediatrics 74: $901-910$.

WILLIAMS, R.S., FERRANTE, R. J., CAVINESS, V.S. JR. (1976). The cellular pathology of microgyria: A Golgi analysis. Acta Neuropathol. (Berl), 36: 269-283.

YAKOVLEV, P.I. and WADSWORTH, R.C. (1946). Schizencephalies. A study of the congenital clefts in the cerebral mantle. Clefts with fused lips. J. Neuropath. and Exp. Neurol. 5: $116-130$. 